\title{
Image Reslicing
}

National Cancer Institute

\section{Source}

National Cancer Institute. Image Reslicing. NCI Thesaurus. Code C94911.

Chang ing from one set of 2D slices to another set. The latter may have a different thickness and/or cut through the subject at a different ang le than the original set. 